\title{
Microstructures and Properties of Ultra-high Strength Steel by Laser Welding
}

\author{
Zhengwei GU, ${ }^{11}$ Sibin $Y U^{1)}$ Lijun HAN, ${ }^{21}$ Jia MENG, ${ }^{11}$ Hong XU1) and Zhenglin ZHANG ${ }^{11}$ \\ 1) Department of Materials Science and Engineering, Jilin University, Nanling Campus, No. 5988 Renmin Street, Changchun, \\ 130025 P. R. China. E-mail: yusibin@126.com \\ 2) The FAW-Volkswagen Automotive Company LTD., No.5, Anqing Road, Dongfeng Street, Changchun, 130042 P. R. China.
}

(Received on November 12, 2010; accepted on April 22, 2011)

\begin{abstract}
Based on the experiments of laser welding of ultra-high strength steel (UHSS), joint morphology, microstructure, hardness and tensile-shear properties are investigated. The results show that the defects such as gas holes and cracks do not appear in the weld metal if the optimized parameters are employed. Microstructures of the weld metal and HAZ are mainly martensite, the widths of martensite lath aren't sensitive to the welding speed. However, the welding speed affects the grain sizes of prior autensite of the weld metal. When changing the welding speed from $20 \mathrm{~mm} / \mathrm{s}$ to $35 \mathrm{~mm} / \mathrm{s}$, the mean widths of prior austenite grains decrease from $10.67 \mu \mathrm{m}$ to $7.68 \mu \mathrm{m}$. In the HAZ, the hardness decreases apparently for the soft ferrite appears. The test results also show that the joint tensile-shear strength can satisfy the demand of production. Consequently, the laser welding quality of UHSS is reliable for manufacturing.
\end{abstract}

KEY WORDS: UHSS; laser welding; microstructures; properties.

\section{Introduction}

In recent years, the problems such as lightness, environmental protection and security have become more important in automotive industry. To reduce the car weight and maintain the function and shock resistance with no cost increasing, some new materials and new forming process are applied. $^{1,2)}$ Quenched ultra-high strength steel EN 10292 TL4225 (simply designated as UHSS) whose tensile strength is more than $1500 \mathrm{MPa}$ is a preferred material for this problem. Compared with the conventional metal such as aluminum or magnesium, UHSS represents better performance and solution to increase the strength-to-mass ratio of sheet components. Therefore, taking ultra-high strength steel as light material is a preferred choice in automotive industry. ${ }^{3,4)}$ However, for the special physical and chemical properties, it is very difficult to connect the UHSS parts with others of body-in-white (BIW) by the conventional welding process. Therefore, new welding process should be adopted for the wide application of UHSS in automotive industry.

Laser welding process is a good solution to this problem for the prominent advantages such as concentrated laser power, high energy, quick speed, small HAZ and fine weld metal quality. ${ }^{5,6)}$ It can satisfy the welding requirements of UHSS theoretically. In this paper, a $4 \mathrm{~kW} \mathrm{Yb:YAG} \mathrm{laser}$ welding system is used to conduct the experiment, the lapwelding joints are made at different welding speed, joint morphology, microstructure, hardness, tensile-shear properties and fracture mode are analyzed and compared. The results indicate that the laser welding joint has good internal quality and mechanical property, and the joint quality can meet the actual production requirements completely.

\section{Experimental Procedures}

\subsection{Laser Welding Equipment}

Yb:YAG laser welding system (HL4006D) emitting at $1064 \mathrm{~nm}$ is adopted to produce the laser welding joints with continuous laser output mode. A self-made jig is used to fix the work-pieces so that the welded bead may become more even and smooth. The gap between the work-pieces is controlled under $0.10 \mathrm{~mm}$.

\subsection{Materials}

The experiment employs the UHSS sheet with thickness of $1.9 \mathrm{~mm}$. It is a kind of boron alloy steel and is often used to make automotive parts by hot-forming process. In the process, the boron alloy steel sheet is firstly heated to 900 $950^{\circ} \mathrm{C}$ in a furnace and austenitized for 5 minutes, and then transferred to a forming die with internal cooling tunnels where it is formed and simultaneously cooled and quenched by the die surfaces. Finally, the microstructure of the steel is transformed into martensite from austenite, so the tensile strength can be improved greatly. For example, the original tensile strength of the steel is about 500-600 MPa, however it can be more than $1500 \mathrm{MPa}$ after being quenched by the hot-forming process. $^{7-10)}$ The main chemical compositions and mechanical properties of UHSS are shown in Table 1 and Table 2 respectively.

\subsection{Experimental Method}

The maximum output power $4 \mathrm{~kW}$ is used. High power 
condition can increase the agitation of molten pool, which is helpful to reduce the occurrence of gas hole. Laser beam is focused to a spot with the diameter of $1 \mathrm{~mm}$. The employed welding parameters are shown in Table 3. The lap welding process is employed in this experiment and the specimen is shown in Fig. 1. To reduce the welding defects, the specimens are cleaned and kept dry before welding.

Table 1. Chemical compositions of UHSS.

\begin{tabular}{lcccccccccccc}
\hline UHSS & $\mathrm{C}$ & $\mathrm{Mn}$ & $\mathrm{Si}$ & $\mathrm{P}$ & $\mathrm{S}$ & $\mathrm{Al}$ & $\mathrm{Ti}$ & $\mathrm{Cr}$ & $\mathrm{B}$ & $\mathrm{Mo}$ & $\mathrm{Cu}$ & $\mathrm{Ni}$ \\
\hline Min. & 0.22 & 1.20 & 0.2 & - & - & 0.02 & 0.02 & 0.11 & 0.002 & - & - & - \\
Max. & 0.25 & 1.40 & 0.3 & 0.02 & 0.005 & 0.05 & 0.05 & 0.20 & 0.0035 & 0.10 & 0.10 & 0.10 \\
\hline
\end{tabular}

Table 2. Mechanical properties of UHSS.

\begin{tabular}{ccc}
\hline Yield strength $(\mathrm{MPa})$ & Tensile strength $(\mathrm{MPa})$ & Elongation (\%) \\
\hline 1200 & 1500 & 9.8 \\
\hline
\end{tabular}

Table 3. Laser welding parameters.

\begin{tabular}{cccc}
\hline Specimen & Power & Spot dimension & Welding peed \\
\hline 1 & $4 \mathrm{~kW}$ & $1 \mathrm{~mm}$ & $\mathrm{~V}_{1}=20 \mathrm{~mm} / \mathrm{s}$ \\
2 & $4 \mathrm{~kW}$ & $1 \mathrm{~mm}$ & $\mathrm{~V}_{2}=25 \mathrm{~mm} / \mathrm{s}$ \\
3 & $4 \mathrm{~kW}$ & $1 \mathrm{~mm}$ & $\mathrm{~V}_{3}=30 \mathrm{~mm} / \mathrm{s}$ \\
4 & $4 \mathrm{~kW}$ & $1 \mathrm{~mm}$ & $\mathrm{~V}_{4}=35 \mathrm{~mm} / \mathrm{s}$ \\
\hline
\end{tabular}

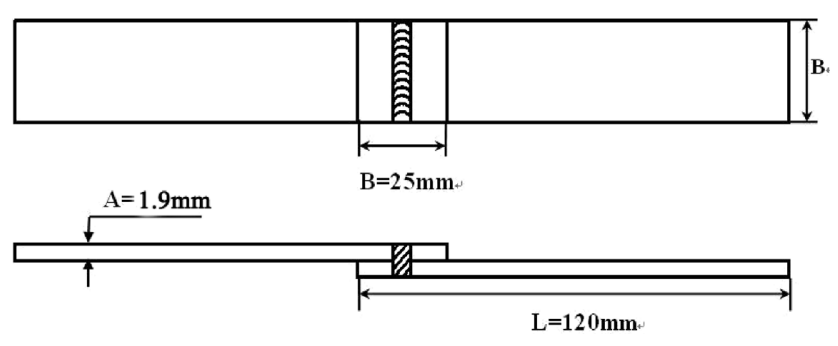

Fig. 1. Joint design of the specimen.

\section{Results and Discussions}

\subsection{Joint Morphology}

The welded joints are made at different welding speed. Over-views and cross-sections of the welded beads are shown in Figs. 2 and 3 respectively. From Fig. 2 it can be seen that the higher welding speed results in the narrower color-changed zone of the welded bead. It is mainly because of the lower heat input resulting from the higher welding speed. From Fig. 3 it can be seen that there are no defects such as gas holes and cracks in the welded bead. The results also show that the size of welded bead is sensitive to the welding speed. When the welding speed of $20 \mathrm{~mm} / \mathrm{s}$ or $30 \mathrm{~mm} / \mathrm{s}$ is used, full penetration is observed. When it reaches to $35 \mathrm{~mm} / \mathrm{s}$, partial penetration of $3.5 \mathrm{~mm}$ (full penetration is $3.8 \mathrm{~mm}$ ) is observed. At the welding speed of $20 \mathrm{~mm} / \mathrm{s}$, the welded bead has bigger size and better fusion, because there is enough time for the metal to be fused. The intermediate tendon area shown in Fig. 3 becomes more apparent with the improvement of the welding speed, which can increase the risk of hot crack and reduce the tensile strength for the reason that the opposite growth grains will not fuse together entirely. ${ }^{11)}$

\subsection{Microstructure}

Figure 4 illustrates a typical microstructure of the base metal. It can be seen that the major microstructure is martensite which makes the base metal exhibit high strength. Microstructures of the weld metal at different welding speed by SEM are shown in Fig. 5. It indicates that the weld metals are characterized by martensite which are similar to the base metal. The martensitic structure can make the weld metal behave wonderful strength and hardness. Microstructure of the weld metal mainly depends on the chemical compositions and the heat input of welding. The high selfquenched rate associated with the laser welding process promotes the diffusionless transformation of the prior autensite into martensite. Figure 5 also indicates that the widths of martensite laths are not sensitive to the welding speed and the changes are not obvious when the different welding

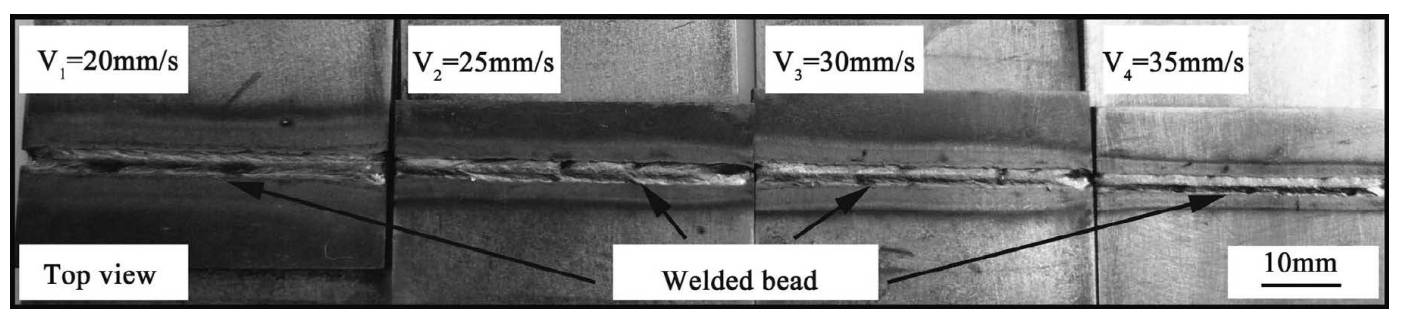

Fig. 2. Over-views of the welded bead at different welding speed.

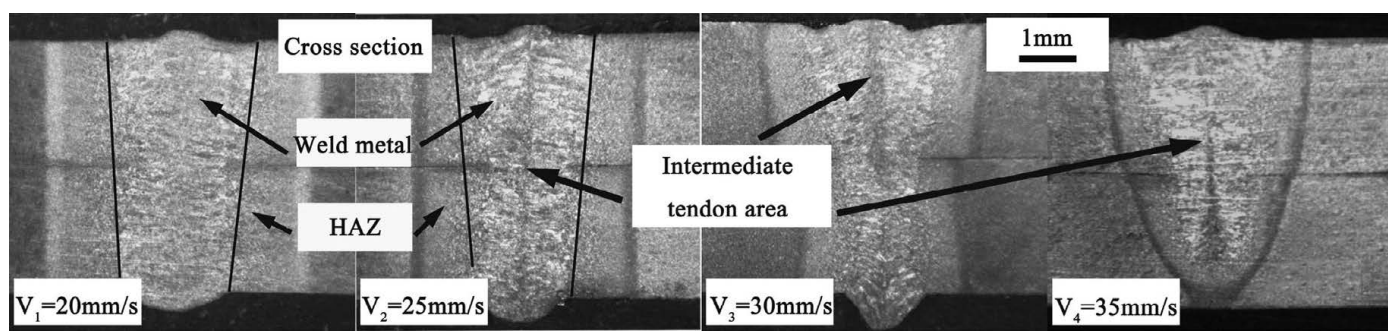

Fig. 3. Cross-sections of the welded bead at different welding speed. 
speed is used. The test widths of martensite laths lie between $0.58-1.26 \mu \mathrm{m}$.

The prior autensite microstructures of the weld metals at different welding speed are shown in Fig. 6. For the heat flow in the weld metal is generally highly directional toward the adjacent cold metal, prior austenite develops distinct columnar grains. The welding speed affects the grain size of prior austenite. When changing the welding speed from $20 \mathrm{~mm} / \mathrm{s}$ to $35 \mathrm{~mm} / \mathrm{s}$, the mean widths of the prior austenite

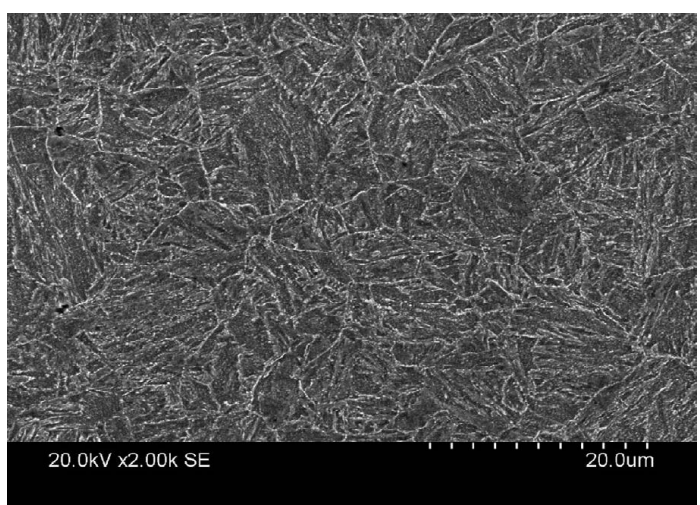

Fig. 4. Microstructure of the base metal. grains decrease from $10.67 \mu \mathrm{m}$ to $7.68 \mu \mathrm{m}$. It can be explained that the welding molten pool retains at high temperature for shorter time resulting from the high welding speed and the cooling rate is relatively high, the grains therefore grow slowly.

Microstructures of the HAZ are crucial to the mechanical properties of the welded joints. SEM images of HAZ at different welding speed are shown in Fig. 7. It can be found that the major microstructures are still martensite. The main reason is that the initial martensite is formed into austenite and the subsequent cooling causes the austenite transform into martensite again. The widths of martensite laths are not sensitive to the welding speed either. The test values of martensite lath widths lie between $0.64-1.72 \mu \mathrm{m}$.

\subsection{Hardness}

Figure 8(a) shows the hardness distribution of the weld metal along the penetrated direction. The hardness distributions are uneven. The weld metal exhibits higher hardness than the base metal due to the high cooling rate. Figure 8(b) shows the hardness distributions from the weld metal to the base metal. At the area of the weld metal and its approaching HAZ, the hardness changes are not obvious resulting from the same martensitic microstructure. However, it decreases sharply at the area of the HAZ near the base met-
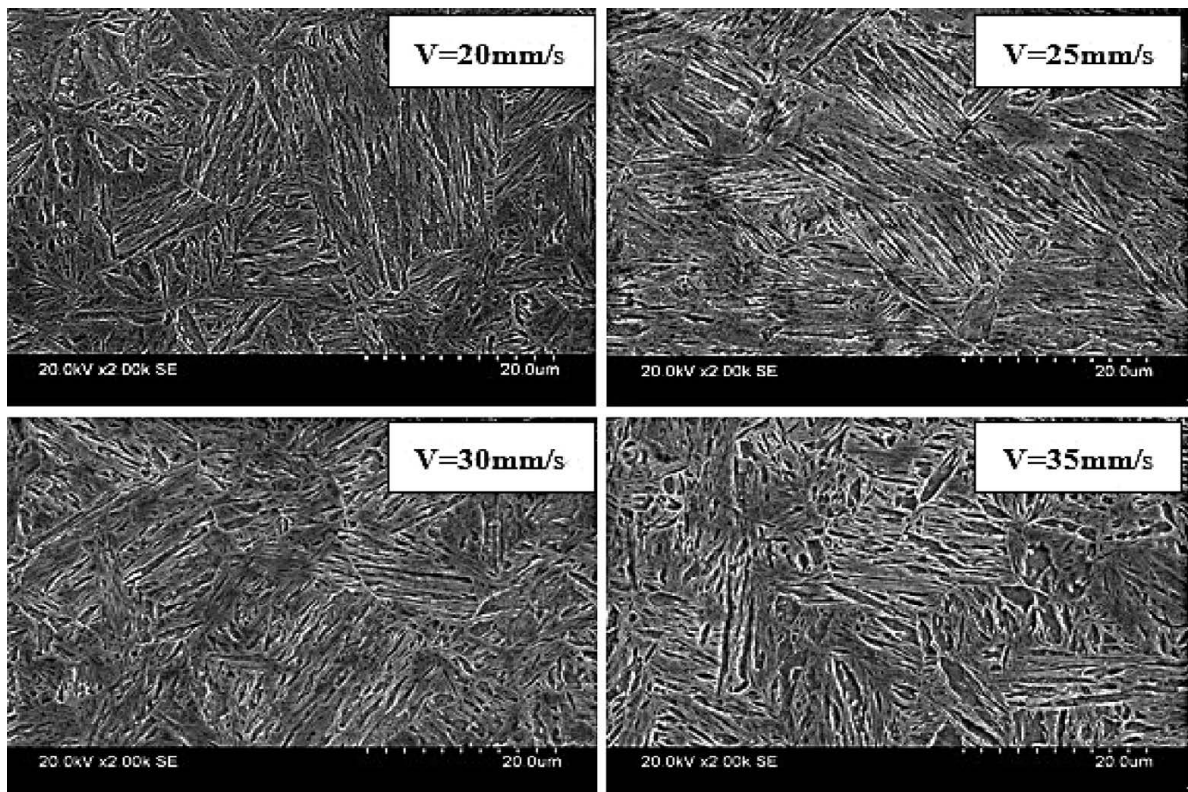

Fig. 5. SEM miages of the weld metal.
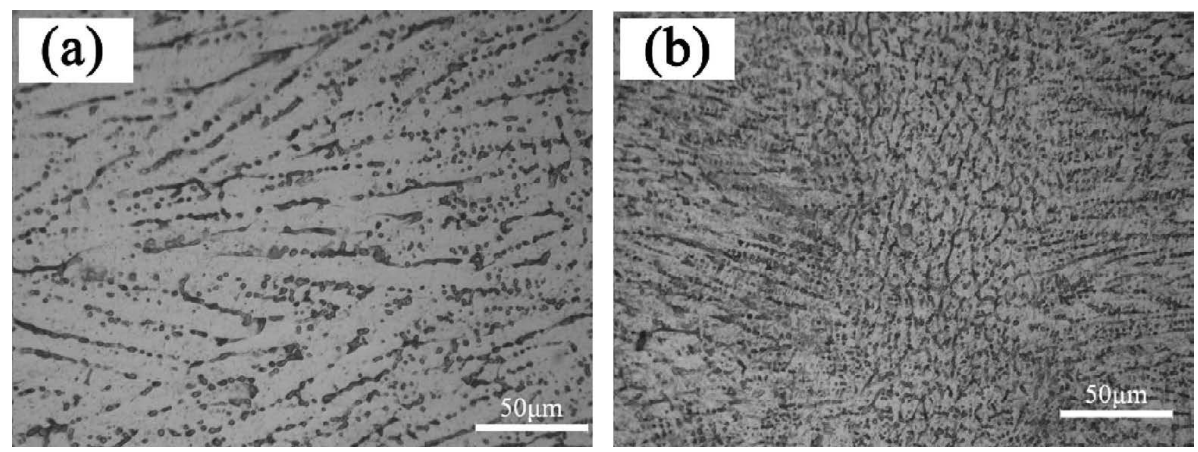

Fig. 6. Optical micrographs of prior autensite of the weld metal. (a) welding speed of $20 \mathrm{~mm} / \mathrm{s}$, (b) welding speed of $35 \mathrm{~mm} / \mathrm{s}$. 


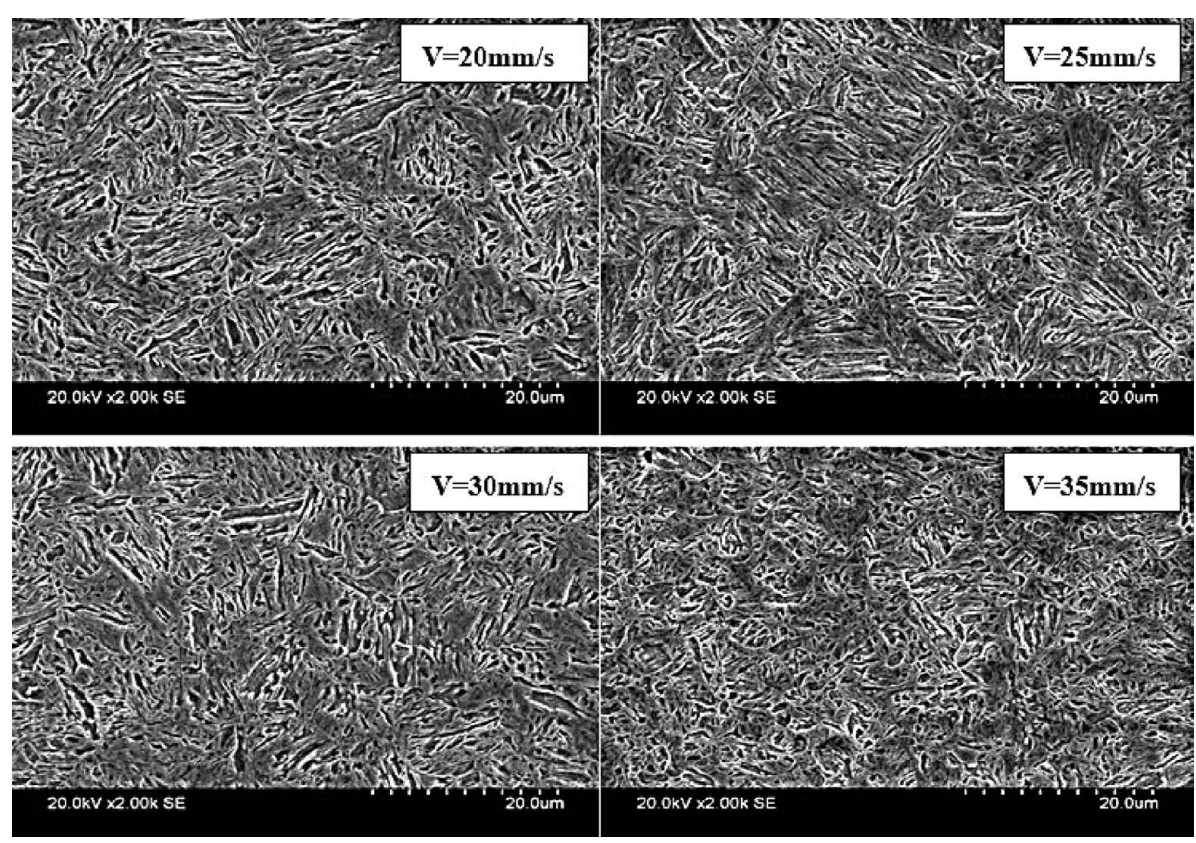

Fig. 7. SEM images of the HAZ.
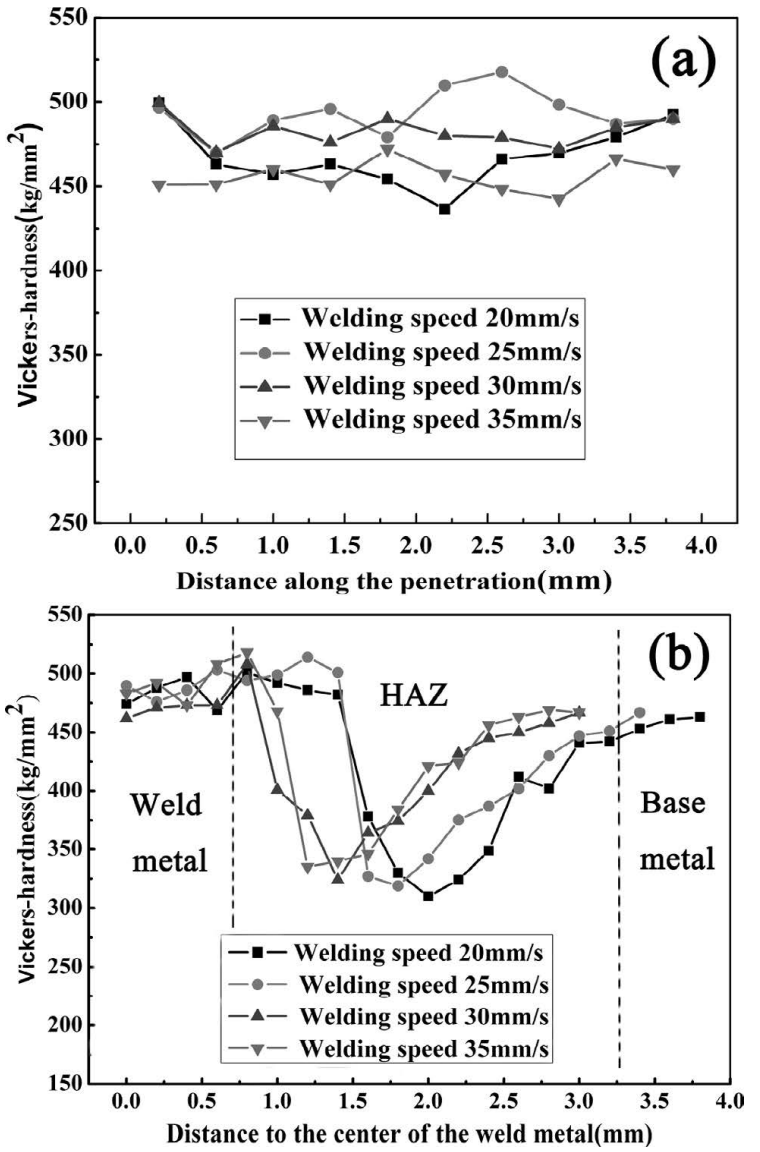

Fig. 8. Hardness profiles of the joints. (a) hardness of the weld metal along the penetration, (b) hardness from the weld metal to the base metal.

al. The minimum hardness is located at the area where the peak temperature correlates to the base metal's $\mathrm{Ac}_{1}$. It is only about $320 \mathrm{HV}$, less than that of base metal (460 HV). The main reason is that some ferrite forms at the softening area after welding (Seen in Fig. 9). The base metal is a kind of quenched steel and the tempered zone will exist in the

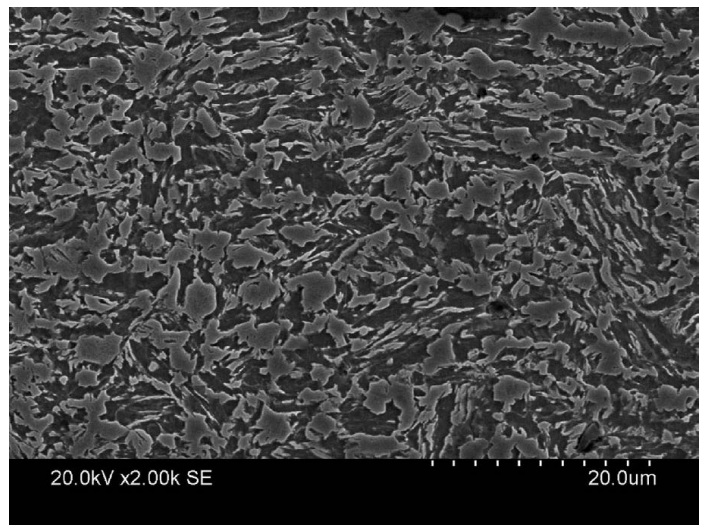

Fig. 9. Microstructure of the softening area.

Table 4. Effect of welding speed on tensile-shear properties.

\begin{tabular}{ccc}
\hline Welding speed $(\mathrm{mm} / \mathrm{s})$ & Tensile-shear strength $(\mathrm{MPa})$ & Elongation (\%) \\
\hline 20 & 869 & 13 \\
25 & 833 & 11.4 \\
30 & 825 & 7.9 \\
35 & 861 & 4.9
\end{tabular}

HAZ after welding. For the low heat input in this area, the steel can only be heated to a temperature below $\mathrm{Ac}_{1}$, the martensite is therefore decomposed into ferrite. The change of the microstructure results in the change of the mechanical propertiy, causing the softening phenomenon in HAZ.

\subsection{Tensile-shear Test and Fracture Mechanism}

To investigate the mechanical properties of lap-welding joints, tensile-shear tests are carried out on Zwick-Z100 machine. The stretching speed is $20 \mathrm{~mm} / \mathrm{min}$. The tensileshear properties of the joints made at different welding speed are shown in Table 4. The test results indicate that the welding speed affects the tensile-shear strength of the joints. The strength of the joint made at the welding speed of 
$20 \mathrm{~mm} / \mathrm{s}$ is the highest. At the low welding speed, there is enough time for the metal to be fused, the opposite growth grains integrate better and the intermediate tendon area nearly disappears (seen in Fig. 3). With the increasing of welding speed, the intermediate tendon area becomes more apparent, which makes the tensile-shear strength decrease. For the joint made at the welding speed of $35 \mathrm{~mm} / \mathrm{s}$, its intermediate tendon area mainly lies in the lower sheet instead of in the lap interface, so it has little influence on the tensile-shear strength. In addition, the low heat input might lead to fine grains, the joint tensile-shear strength is therefore increased.

The maximum ductility is obtained when the joint is made at the welding speed of $20 \mathrm{~mm} / \mathrm{s}$. During the freezing, the growing columnar grains push the solutes and impurities to the centre of the weld metal. When the small welding speed is used, the cooling rate is slow and the segregation can be reduced by the diffusing of solutes and impurities, then the ductility is improved.

The macro-fracture image of the tensile-shear specimen is shown in Fig. 10(a). It shows that the fracture happens at the lap interface of the weld metal, not HAZ, though there is a big drop of hardness in HAZ. It is mainly because intensive stress concentration occurs at the lap interface during the tensile-shear process. It can be proved by the simulating results shown in Fig. 11. It can be found that the maximum stress is located at the fusion line and it is much higher than that of the softening region. The initial crack will firstly form in the region near the fusion line (region A shown in Fig. 10(b)) and then propagate to the center of the weld met- al, therefore, the fracture happens at the lap interface.

Figure 12 shows the fracture morphologies of the weld metal edge regions. Some dimples elongated in shear direction and some lack luster regions can be seen. The lack luster regions represent the brittle fracture and the gloss zones represent the ductile fracture. Figure 13 shows the fracture morphologies of the weld metal central regions. Dimples are the primary fracture morphologies. It indicates that the fracture mode is ductile fracture. Figure 13(a) shows the fracture morphologies of the base metal. There are two kinds of equiaxed dimples with different sizes on the fracture surfaces. Densely small dimples distributes around the big dimples. The big dimples can not only be formed by small particles (TiN and AlN etc.), but also can be formed by the

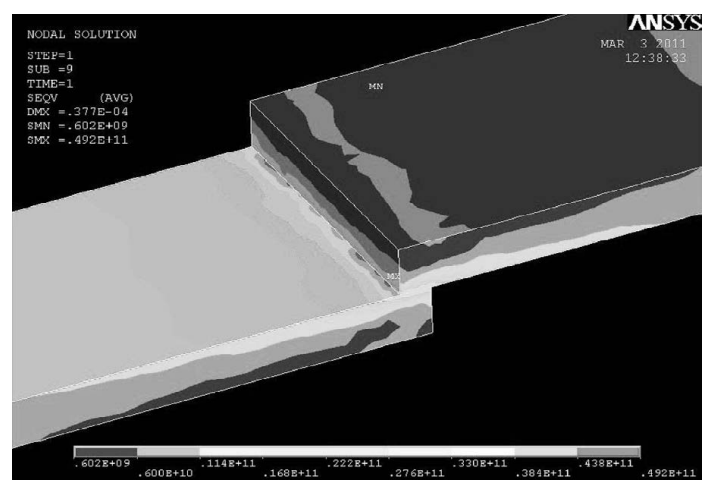

Fig. 11. Stress simulating result of the lap joint in the tensile-shear process.

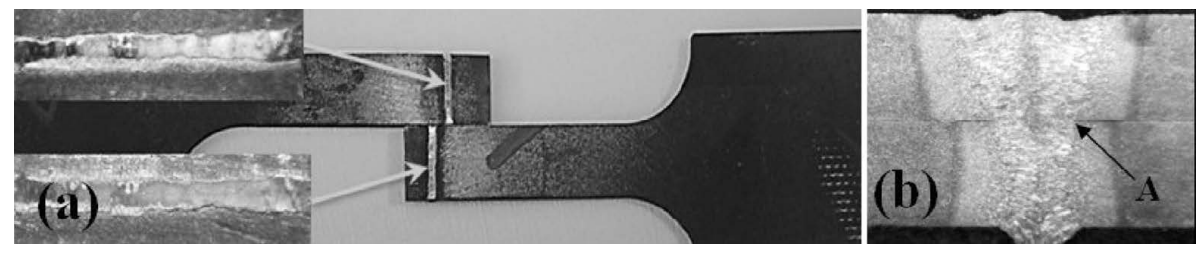

Fig. 10. (a) Macro-fracture image of tensile-shear specimen, (b) starting point of the fracture.
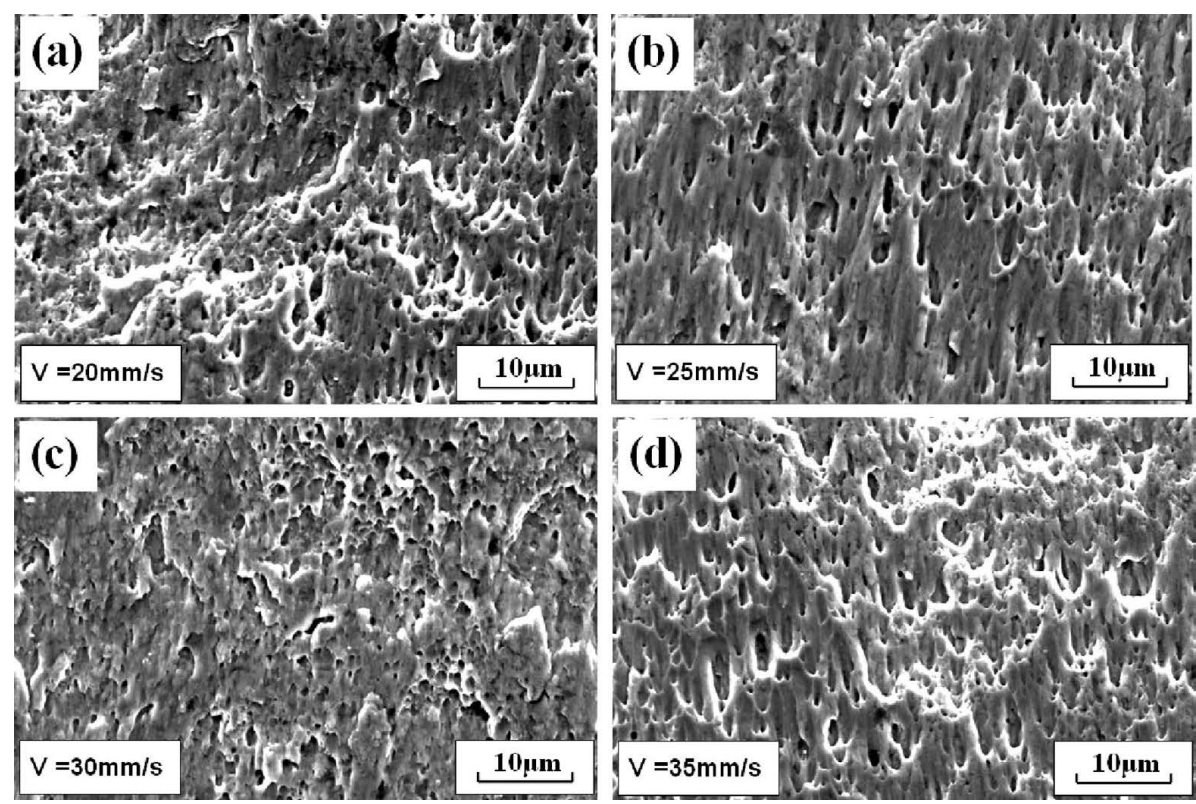

Fig. 12. Fracture morphologies of the edge region of the weld metals at different welding speed. 


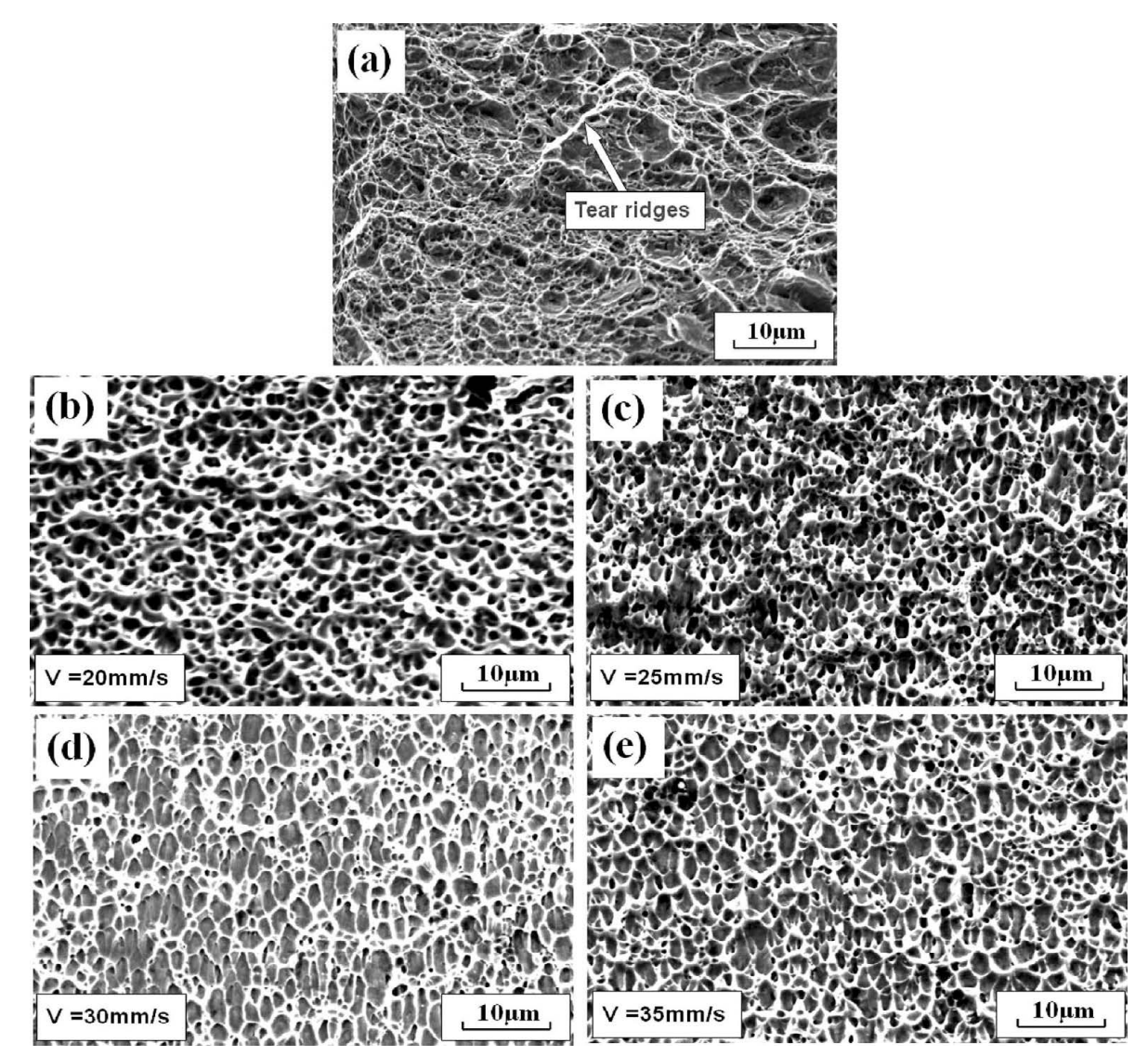

Fig. 13. Fracture morphologies of the base metal and the joints at different welding speed. (a) base metal, (b), (c), (d) and (e) central region of the weld metals.

accumulation of small dimples. ${ }^{12,13)}$ From Figs. 13(b), 13(c), 13(d) and 13(e) we can find that the fracture surface of the joint made at the welding speed of $20 \mathrm{~mm} / \mathrm{s}$ has more uniform and deeper dimples than others and the tear ridges on the dimples connect each other very well, which makes the joint behave wonderful strength and toughness.

\section{Conclusions}

(1) UHSS has good weld-ability under the optimized parameters (Laser power: $4 \mathrm{~kW}$, Spot dimension: $1 \mathrm{~mm}$, Welding speed: $20 \mathrm{~mm} / \mathrm{s}$ ) using the laser welding technology. The tensile-shear strength of lap-welding joints meets the actual production requirement completely. Moreover, the welded joints have good internal qualities, and no internal defects such as cracks and shrinkage holes are found.

(2) The microstructure of the weld metal and its approaching HAZ remains martensite, and the widths of martensite laths aren't sensitive to the welding speed. But the welding speed affects the grain size of prior autensite. When increasing the welding speed from $20 \mathrm{~mm} / \mathrm{s}$ to $35 \mathrm{~mm} / \mathrm{s}$, the columnar grain mean widths of prior austenite decreases from $10.67 \mu \mathrm{m}$ to $7.68 \mu \mathrm{m}$.

(3) The hardness distribution of the weld metal is uneven. Much precipitating ferrite in HAZ near the base metal causes the HAZ softening phenomenon.

(4) The highest strength and the maximum ductility are both obtained when the joint is made at the welding speed of $20 \mathrm{~mm} / \mathrm{s}$. The specimens by different welding speed are all fractured at the lap interfaces of the weld metal. Ductile fracture and brittle fracture consist of the fracture mode.

\section{Acknowledgement}

This work was supported by the Major Technology Program of Ministry of Industry and Information Technology of P.R.China (NO.2009ZX04014-072-01), the Technology Development Program of Jilin Province (NO.20080507) and the Basic Scientific Research Program of Jilin University (NO.20090318).

\section{REFERENCES}

1) A. S. Podder, D. B. Jee and R. K. Ray: ISIJ Int., 47 (2007), 1058.

2) R. S. Sharma and P. Molian: Mater. Des., 30 (2009), 4146.

3) K. Mori, S. Saito and S. Maki: CIRP Annals - Manufacturing Technol., 57 (2008), 321.

4) A. Turetta, S. Bruschi and A. Ghiotti: J. Mater. Process. Technol., 177 (2006), 396.

5) M. Xia, Z. Tian, L. Zhao and Y. N. Zhou: ISIJ Int., 48 (2008), 483.

6) T. K. Han, S. S. Park, K. H. Kim, C. Y. Kang, I. W. Woo and J. B. Lee: ISIJ Int., 45 (2005), 60.

7) A. Yanagida, T. Kurihara and A. Azushima: J. Mater. Process. Technol., 210 (2010), 456.

8) M. Naderi, L. Durrenberger and A. Molinari: Mater. Sci. Eng., 478 (2008), 130.

9) X. Zhu, Z. Ma and L. Wang: Baosteel Technol., 5 (2005), 1.

10) H. J. Wang: Dies Manufacture, 4 (2005), 32.

11) L. Chen, X. Y. Hu and L. J. Hu: Appied Laser, 23 (2003), 19.

12) T. B. Hilditch, J. G. Speer and D. K. Matlock: Mater. Des., 28 (2007), 2566.

13) W. S. Owen, E. A. Wilson and T. Bell: Proc. of 2nd Berkeley Int. Mater. Conf. on High Strength Materials, Wiley, New York, (1965), 167. 